\title{
La pandemia COVID-19 en África: relato de médicos anestesiólogos africanos
}

\section{COVID-19 pandemia in Africa: a narrative review}

\author{
PL. Baele ${ }^{1}$, E. Ahounou ${ }^{2}$, F. Binam ${ }^{3}$, H. Daddy ${ }^{4}$, J. Donamou ${ }^{5}$, ZN. Gathuya ${ }^{6}$, BK. Ki ${ }^{7}$ D Nahimana ${ }^{8}$, \\ BO. Onajin-Obembe ${ }^{9}$, B. Vilasco ${ }^{10}$, E. Zoumenou. ${ }^{2}$
}

\begin{abstract}
The medical experience collected mainly from South-Saharan African countries in relation to the COVID-19 pandemic is presented, where most of the contents described come from scientific publications that appeared during the course of the epidemic (some before peer review), including articles from independent media, along with frequent exchanges of information between the authors, as well as personal testimonies that they themselves have received. No reference will be made to the possible socio-economic consequences of this crisis, although it may be assumed that these will be important, although different from those consequences that will affect technically advanced countries. The stated conclusions belong exclusively to the authors and do not commit, in any way, the institutions in which they form part.
\end{abstract}

\section{Key words:}

Africa,

COVID-19

Anesthesiology, Faculty of Medicine, Catholic University of Louvain (UCLouvain) Belgium.

Faculté des Sciences de la Santé, Université d'Abomey-Calavi, Cotonou, Benin.

Yaounde Faculty of medicine and biomedical Sciences, Cameroon.

Faculté des sciences de la santé. Université Abdou Moumouni, Niamey, Niger.

Service d'Anesthésie-Réanimation, Hôpital Ignace Deen, Université Gamal Abdel Nasser de Conakry, Guinée.

Pediatric Anesthesia, the Nairobi Hospital, University of Nairobi, Kenya.

Service d'Anesthésie-Réanimation, CHU Pédiatrique Charles de Gaulle, Université Ouaga I Pr Joseph Ki-Zerbo, Ouagadougou, Burkina-Faso.

8 CURE Hôpital des Enfants au Niger, Niamey, Niger.

9 College of Health Sciences, University of Port Harcourt, Rivers State, Nigeria.

10 Unité de Formation et de Recherche en Sciences Médicales, Université Félix Houphouët-Boigny d'Abidjan-Cocody, Côte D' ivoire.

Traducción y edición: Dr. Fernando Aranda, Dr. Oneglio Pedemonte

Fecha de recepción: 12 de octubre de 2020

Fecha de aceptación: 12 de octubre de 2010

\section{ORCID}

https://orcid.org/0000-0043-564K

Correspondencia:

PL. Baele

Baele@UCLovain.Be 


\section{RESUMEN}

Se presenta la experiencia médica recopilada principalmente de países del África Sud-Saharina en relación a la pandemia del COVID-19, donde la mayoría de los contenidos descritos provienen de publicaciones científicas aparecidas durante el transcurso de la epidemia (algunos antes de la revisión por pares), incluyendo artículos de medios de comunicación independientes, junto a frecuentes intercambios de información entre los autores, así como, testimonios personales que ellos mismos han recibido. No se hará referencia a las consecuencias socio-económicas posibles de esta crisis, aunque se podrá suponer que estas serán importantes, aunque diferentes a aquellas consecuencias que afectarán a los países técnicamente avanzados. Las conclusiones expuestas pertenecen exclusivamente a los autores y no comprometen, de ninguna forma, a las instituciones en las cuales ellos forman parte.

\section{Palabras clave:}

Africa, COVID-19

\section{Contexto geográfico, humano y político}

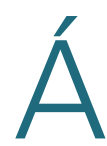
frica es un continente gigantesco con una superficie levemente superior a los 30 millones de kilómetros cuadrados, donde viven cerca de 1.200 millones de habitantes (el país más poblado es Nigeria con 206 millones de habitantes). Tiene una geografía muy diversa: una zona tropical, que es el África central, rodeada al norte y al sur por zonas semidesérticas (sabanas), luego una zona desértica, una zona mediterránea y los países del cono sur del continente. Este último segmento corresponde a la latitud de Uruguay en América Latina.

El crecimiento demográfico es enorme en el África sub-Sahara, donde cada mujer tiene en promedio 4 hijos, llevando a que el continente tenga cerca de 1.200 millones de habitantes. En relación a la distribución de ellos, se asemeja en algo a América Latina, ya que la población se tiene a acumular en grandes metrópolis cercanas a la zona costera (Figura 1).

Estas ciudades estratégicamente ubicadas, fueron en el pasado ciudades de intercambio de esclavos; destacando aparte del hacinamiento, el calor y la humedad, una compleja geografía compuestas de manglares, lagunas, islas y archipiélagos, donde pululan los mosquitos que provocan la Malaria, enfermedad que producirá cerca de 800.000 decesos de africanos en el 2020; dos terceras partes de estos fallecimientos corresponderán a niños menores de cinco años (Figura 2).

Cada país de ese continente es igualmente diferente a lo que observamos en América Latina. Aparte de Etiopía que nunca fue colonizado, todos los demás países tuvieron luchas terribles; incluyendo guerras civiles, feroces combates para obtener la independencia, provocado muchos de ellos por los protagonistas de la guerra fría que no solo pretendían el botín del petróleo, sino que también: uranio, diamantes, piedras preciosas, cobre, bauxita, fosfato y otros. Casualmente, un nuevo participante hegemónico que está invadiendo el continente también viene de Asia, y así es como China ha establecido una nueva forma de dominio, llevando a que muchos ya hablen del concepto "China-áfrica"[1], que de alguna manera también genera dependencia.

\section{Contexto cronológico de la epidemia}

Gran parte de África (como en muchas partes del mundo) supo con bastantes semanas de retraso de la epidemia que se había originado en Wuhan (China). Todos recordamos ese hospital de 1.000 camas que tuvieron que construir en apenas de 10 días, junto con el confinamiento severo de toda su población para superar la crisis, sumado al cierre inmediato de fronteras, lo que generó en África una serie de temo-

Las cifras y los gráficos que se citan provienen del sitio Our World in Data y de SDG (Sustainable Development Goal) Tracker, quienes se presentan de la siguiente forma:

"Our World in Data and the SDG-Tracker are collaborative efforts between researchers at the University of Oxford, who are the scientific editors of the website content; and the non-profit organization Global Change Data Lab, who publishes and maintains the website and the data tools that make our work possible. At the University of Oxford we are based at the Oxford Martin Programme on Global Development". 


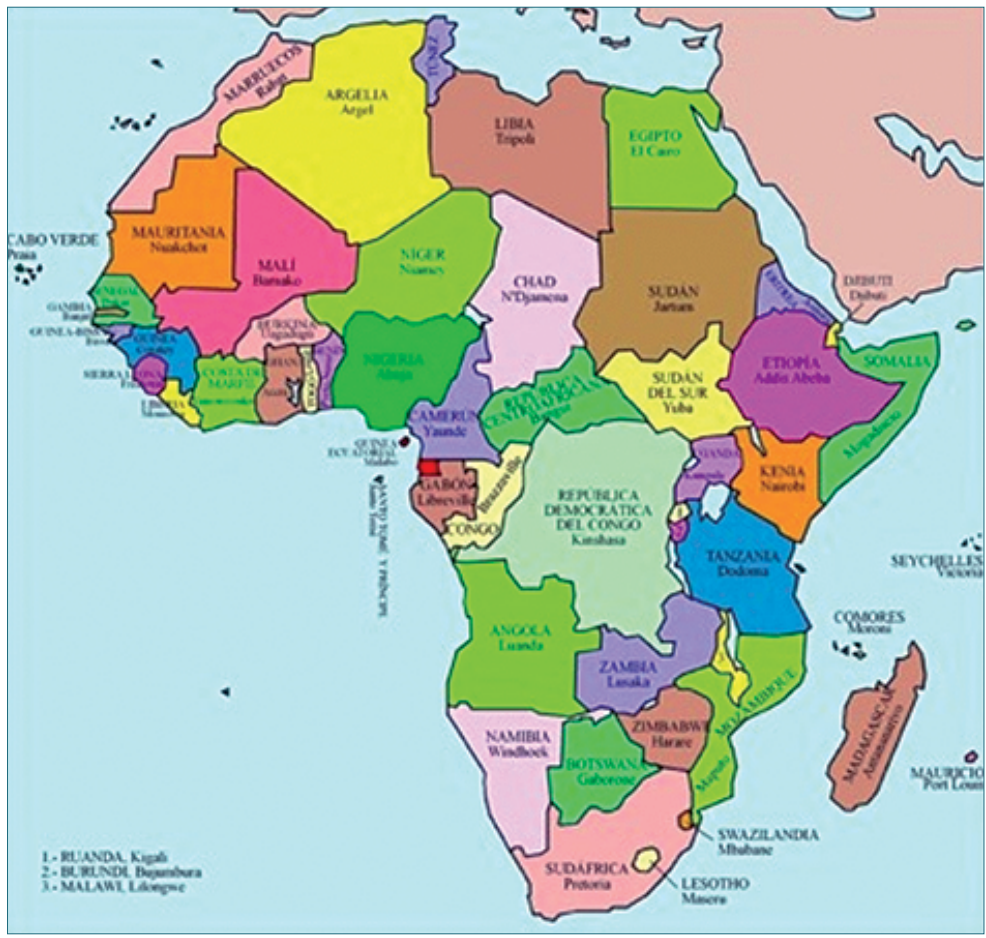

Figura 1. Mapa político actual de África.

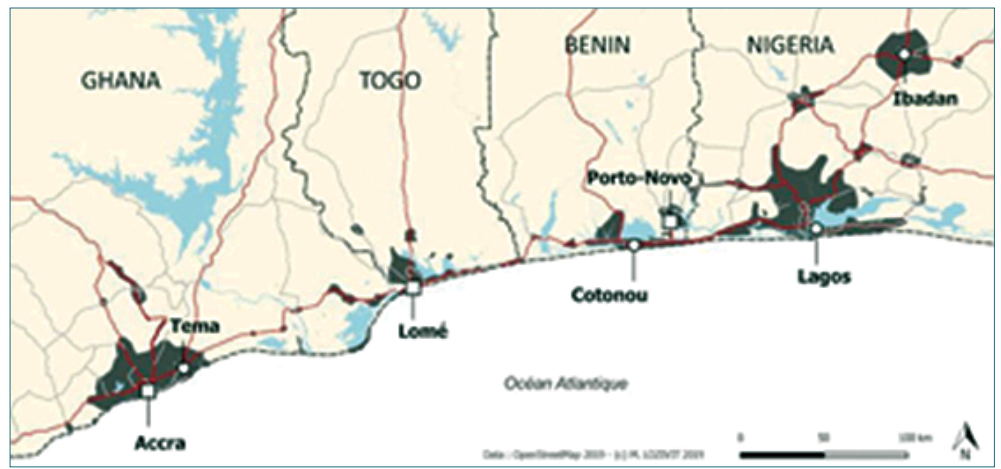

Figura 2. Densidad poblacional en algunas ciudades del África del oeste.

res justificados, ya que la capacidad de cualquier país para llegar a esa capacidad de respuesta era impensada. Mayor aún fue el temor, cuando la sólida salud pública europea no pudo contener en forma oportuna y rápida los contagios producidos por el virus SARS-CoV-2. Igual que en América Latina, los africanos observaban que la Lombardía en Italia sucumbió y que poco tiempo después a Bélgica, Francia, Inglaterra, España y a Estados Unidos también les pasó lo mismo. Sin embargo, ellos también observaron la ausencia de medidas precoces en Europa: como el cierre de fronteras, equipos de protección (EPP) para el personal de salud, disponibilidad de test, no tener una reserva de mascarillas suficiente, incluso de medicamentos y ventiladores mecánicos. A eso se agrega la ausencia de fronteras en los espacios del acuerdo de Schengen que había sido hasta ese momento respetado por 26 países del viejo continente, sumado a la subestimación tanto por políticos como por los expertos. Todo esto fue analizado con mucha atención y preocupación por las autoridades y médicos del casi toda el África. 


\section{Pronósticos pesimistas para África}

Muchos pensaron desde el inicio que al igual que las gripes estacionales, el SARS-CoV-2 soportaría mal el calor subsahariano. Sin embargo, la forma de presentación en países como Irán, Irak, Kuwait y Arabia Saudita que fueron severamente afectados provocó dudas.

También se pensó que la variedad de receptores en los alveolos pudiese ser distinta; sin embargo, investigaciones realizadas en Bélgica (Universidad de Gantes) apuntaban a lo contrario y muchas otras teorías se especularon antes de la llegada del virus[3]-[5].

La realidad era que los servicios de salud africanos son extremadamente precarios[6]; con personal poco numeroso y formado, hospitales subequipados, aprovisionamiento aleatorio de medicamentos, materiales de uso clínico reesterilizados y con muy pocas camas de cuidados intensivos. Por otro lado, las condiciones generales impactarían severamente la economía informal haciendo casi imposible el confinamiento: el hacinamiento no respetaría el distanciamiento social, la falta de agua potable para el lavado de manos, la ausencia de coberturas de salud, sumado a una infraestructura de salud, de transporte, de caminos y de logística mínima.

Lamentablemente, junto a todo la anterior, estaban los antecedentes de recientes epidemias que han traído resultados desastrosos, como, por ejemplo: la Malaria, el SIDA, la Esquistomatosis, la Tuberculosis multirresistente y el Ébola. Todas estas enfermedades prevalentes se podrían complicar mutualmente, y que de hecho llevó a una serie de "muertes colaterales", debido a la ausencia de la cobertura de salud habitual[6].

Por todas las razones anteriormente enunciadas, el ingreso del COVID-19 en África según los expertos internacionales, hacía presagiar una mortalidad inconmensurable, mucho más dura que en otros continentes.

Por el contrario, hay que reconocer que las autoridades de este continente están mucho más habituadas a situaciones epidémicas. La población misma conoce y responde con rapidez frente a emergencias sanitarias o de la propia naturaleza, como son las medidas ya conocidas: el refugio y el aislamiento de comunidades enteras (y también de pacientes), la restricción de movilidad, el cierre de las fronteras y los estados de sitio. A eso se agrega los fondos de libre disposición de la ayuda internacional dedicados a desastres, los cuales lamentablemente, no siempre llegan a los lugares de destino.

\section{La llegada del COVID-19 al África subsahariana}

La mirada de occidente, convencidos en la fortaleza de su sistema de salud y sus capacidades financieras, respaldados por una robusta infraestructura de hospitales y equipamiento sofisticado, quizás olvidaron o menospreciaron la relevancia de la salud primaria, indispensable en la prevención de este tipo de epidemia (Tabla 1). En cambio, los gobiernos africanos conscientes de sus capacidades curativas insuficientes, implementaron medidas preventivas basada en los siguientes aspectos[10]:

- Cierre de la fronteras aéreas y marítimas: todo pasajero que llegó, debió cumplir cuarentenas en hoteles, siendo solo liberados con una RT-PCR (-).

- En caso de test RT-PCR (+): las personas asintomáticas fueron llevadas a hospitales pequeños fuera de las grandes ciudades. Paralelamente, los pocos hospitales existentes se dedicaron al manejo de los pacientes COVID-19 sintomáticos únicamente.

- La mayoría de los países impusieron la utilización de las mascarillas en los lugares públicos, popularizando estas medidas con canciones alusivas a su uso. Las propias autoridades portaron mascarillas y las repartieron gratuitamente a la gente, dando un verdadero ejemplo.

- El transporte público funciono muy restringido.

- La mayor parte de los países optó por el confinamiento localizado, incluso en algunos casos utilizaron el confinamiento separado entre hombres y mujeres, e incluso por distintos segmentos etarios.

- El cierre del comercio no esencial aconteció solo en la mitad de los países, todo ellos eso si, instaurando un estado de sitio nocturno.

- La mayor parte de los países cerraron inmediatamente las escuelas y universidades, aunque algunos tardaron en tomar esta medida (Figura 3).

Todas estas instrucciones acarrearon severas consecuencias económicas que fueron aceptadas por la población, y solo hubo pequeñas escaramuzas de rebelión callejera, que pedían fundamentalmente aliviarlas. Los controles policiales casi siempre fueron violentos, tanto es así, que la Comisión de Derechos Humanos de Nigeria denunció la muerte de 18 personas que no respetaron el confinamiento. En otros países esta represión violenta fue menor.

Ninguno de los entrevistados de los distintos países señaló que les haya faltado el examen de RT-PCR para el testeo de los sintomáticos, que como se sabe por las estadísticas no fueron tantos, quizás producto del cierre precoz de fronteras y la obligatoriedad temprana del uso de la mascarilla. 


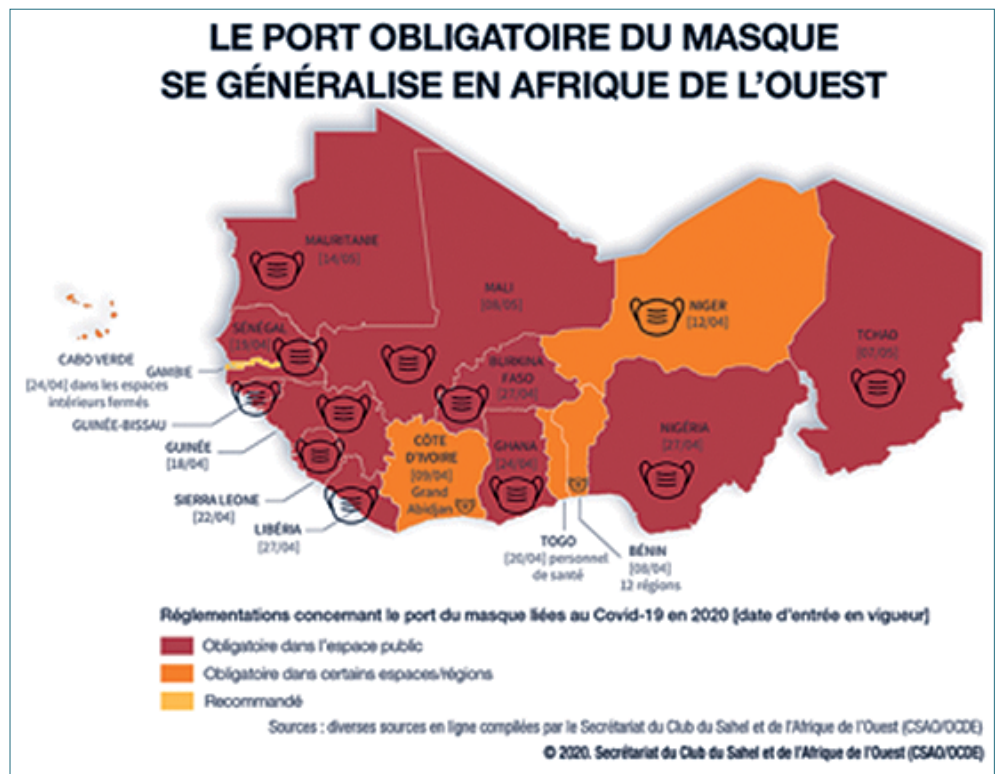

Figura 3. Uso obligatorio de mascarilla facial en África del oeste.

\begin{tabular}{lcllr}
\multicolumn{6}{l}{ Tabla 1. Fallecimientos por COVID-19 por millón de habitantes en algunos países clasificados por } \\
región
\end{tabular}

(Our world in data, 1 septiembre 2020).

* Bélgica incluye también las muertes sospechosas COVID-19 que no han sido testeadas.

\section{La propagación del COVID-19 en África}

Los primeros casos en esta parte de África provinieron de Italia a fines de febrero y los primeros fallecidos a fines de marzo, siendo alrededor de un mes de diferencia con lo que pasó en Europa. Los primeros casos graves se presentaron en el seno de las clases privilegiadas que viajan cotidianamente, miembros de los gobiernos, jefes de empresas y de organizaciones internacionales. Es probable, que algunas de las victimas lograran franquear los controles fronterizos, transformándose éstos en los primeros focos 
de contaminación. Esto alimentó la creencia que era una enfermedad de ricos y particularmente en África. también de los blancos y de personas poderosas que no obedecieron las medidas de prevención impuestas.

La gran mayoría de los países del África subsahariana lograron aplanar la curva, cuya tasa de mortalidad fue baja, 30 a 40 veces más baja que en los principales países europeos. A pesar de todo, hospitales de Guinea, Liberia y Sierra Leona desbordaron y estuvieron al borde del colapso[11]; algunos pacientes agonizaban en las salas de urgencia, otros fallecieron en su domicilio. A pesar que estos no eran muchos, la debilitada infraestructura y la carencia del recurso humano impedían una atención oportuna, que, por fortuna para ellos, lo lograron superar en pocos días (Figura 4).
Los colegas que participaron y testimoniaron en este artículo señalan que efectivamente faltaron EPP, principalmente por la insolvencia económica y crediticia de la mayoría de estos países, sumado también a representar un mercado menor para los países proveedores. A pesar de ello, los africanos recurrieron a la producción local, artesanal, tanto para la confección de mascarillas como delantales de protección. Nos señalaron también los colegas africanos, que este tipo de emprendimiento artesanal son abundantes en estos países, y que, gracias a ellos pudieron subsistir.

Contaron también con la ayuda de algunas organizaciones internacionales: ONG, OMS, de algunos estados más ricos, y de la Fundación Rey Balduino de Bélgica entre otros. Además, muchos tenían reservas del material que utilizaron durante la epidemia del Ébola

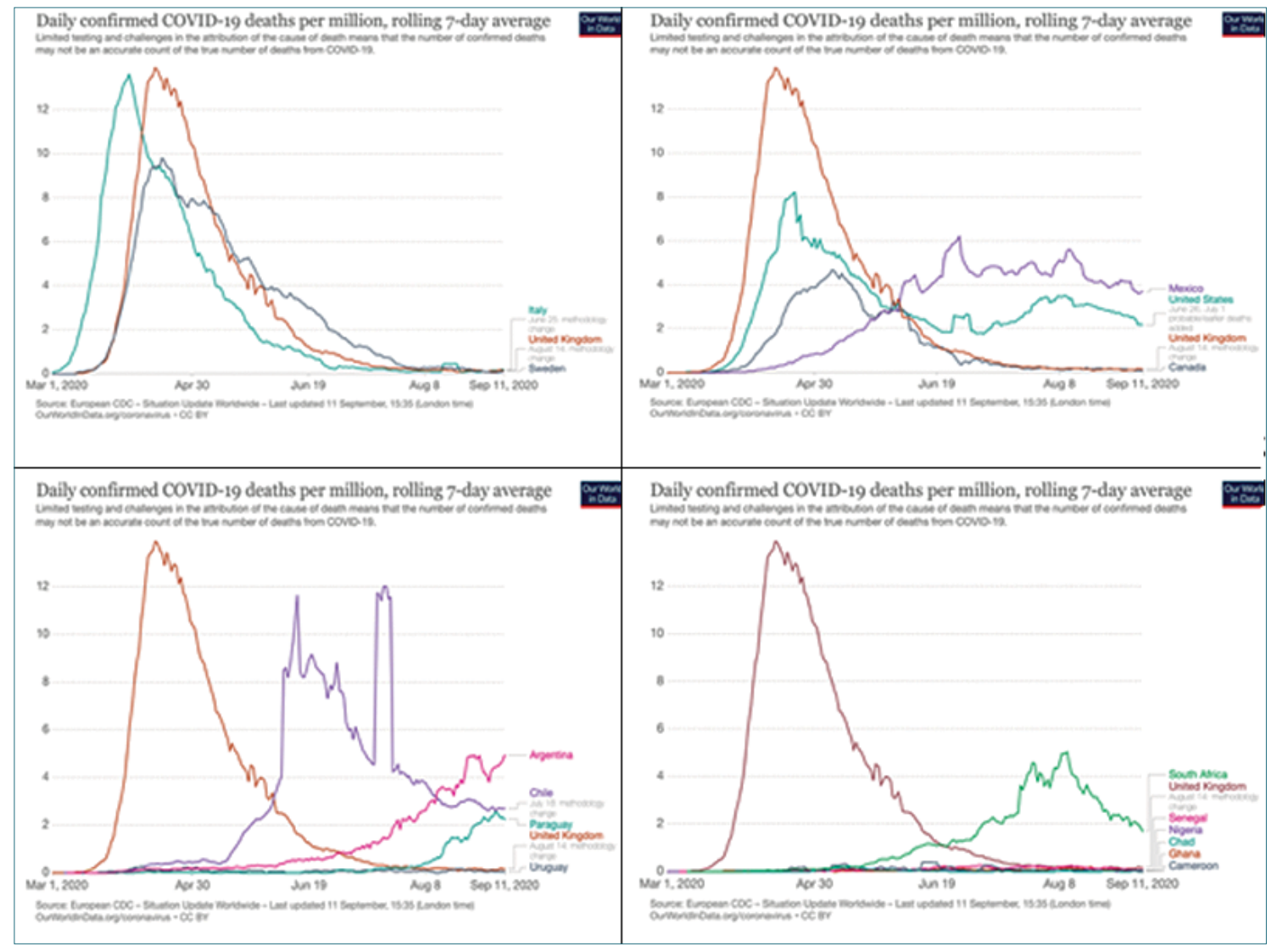

Figura 4. Comparación de la evolución de la mortalidad por COVID-19 en distintos continentes. Europa arriba a la izquierda, Norteamérica arriba a la derecha, Sudamérica abajo a la izquierda y África sub-sahariana abajo a la derecha. El Reino Unido (en color café) sirve de punto de comparación común. En estos gráficos se distingue que a diferencia de los otros continentes, el África sub-sahariana ha sido poco tocada por la pandemia. Color Café: obligatorio en espacios públicos. Color Naranjo: obligatorio en ciertos espacios/regiones. Color Amarillo: recomendado. 
en el 2013, que parecían haber sido algo exageradas para el control de este virus según los participantes.

No hubo grandes pérdidas de vidas humanas en los equipos de salud de la atención pública. Lo que si afectó la atención de salud de los pacientes, fue que muchos equipos médicos completos se fueron a trabajar a clínicas privadas para atender a pacientes privados o aquellos que no pudieron atenderse en el sistema público, con el objeto de tener mayores ingresos, abandonando la salud pública.

El peak de la pandemia en África, igual que en Chile, ocurrió en los meses de junio y julio, o sea, 2 a 3 meses posterior a la observada en Europa. Aunque es probable que algunos países todavía no alcancen el peak en septiembre.

Los médicos africanos estuvieron siempre atentos a las terapias que se estaban probando en los países más desarrollados y las aplicaron en los pacientes hospitalizados: los corticoides en altas dosis, la anticoagulación en dosis terapéuticas, algunos recurrieron al plasma de convalecientes con el objeto de evitar que los pacientes llegaran a la ventilación mecánica (sabiendo ellos, que los resultados de esta técnica eran extremadamente malos y el recurso escaso). En los casos menos sintomáticos, muchos de estos países recurrieron a la Hidroxicloroquina como tratamiento inicial, medicamento que los africanos conocen extremadamente bien desde muchos decenios.

Por desgracia, será poco probable que estos buenos resultados sean publicados, ya que ninguno de ellos pudo realizar trabajos aleatorios y el mundo probablemente no conocerá esta enorme experiencia clínica (Figura 5).

\section{Algunos comentarios del Norte y del Sur del continente}

En África del norte la pandemia evoluciona de manera diferente: el virus dejó muchas más víctimas, aunque no tanto como en Europa o en América. Se apreció que en Argelia, Tunes y Marruecos tuvieron un recorrido de la pandemia al inicio privilegiado, hasta que relajaron algunas medidas de precaución, como ocurrió por ejemplo, con los permisos otorgados para festejar la mayor celebración de los musulmanes, la llamada Aid al-Kebir (fiesta del sacrificio) a mediados de julio. Tanto es así, que el propio rey de Marruecos tuvo que intervenir y utilizar las fuerzas armadas para controlar la población imponiendo medidas estrictas.

En África del sur, la pandemia siguió un recorrido típico a un país desarrollado. Su situación geográfica la ha convertido en un eje comercial extremadamente importante, siendo punto de tránsito hacia el oriente por vía marítima o aérea, tanto de hombres de negocios como de trabajadores de todo el mundo. Por lo tanto, fue imposible tomar medidas preventivas más severas, introduciéndose el virus de esta manera en la población vulnerable, influyendo sin duda la alta concentración demográfica de las grandes ciudades, la pobreza y los "townships" (campamentos). El confinamiento produjo miseria y hambre que provocó la rabia y cólera de muchos de sus habitantes. A pesar que África del sur tiene un excelente sistema de salud, el acceso es muy desigual, lo que ha significado que, por lejos, ha sido el país más afectado de todo el continente.

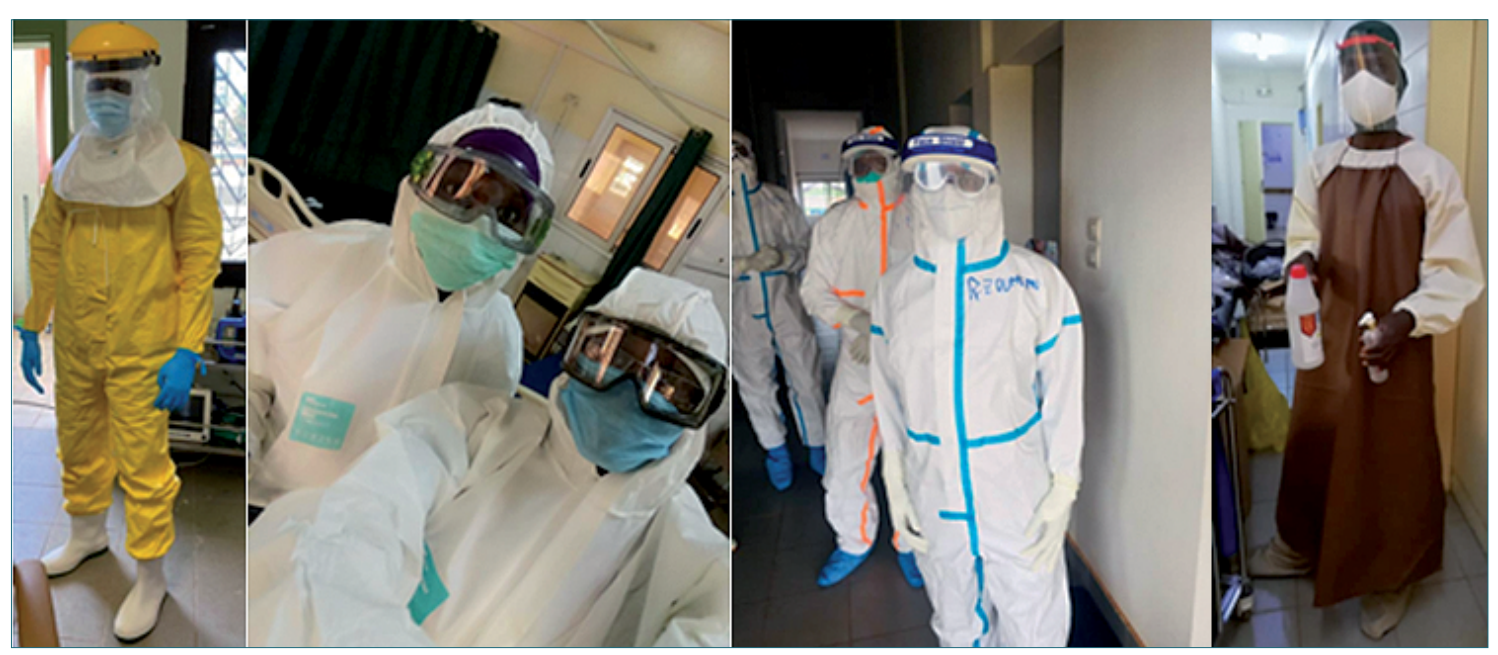

Figura 5. Tenidas anti-Ébola de Guinea, Niger, Benín y Burkina-Faso. (fotos: Donamou, Niandou Zoumenou y Ki). 


\section{¿Cómo se explica la baja mortalidad del COVID-19 en África subsahariana?}

Primero, debemos decir que no parece haber una menor tasa de contagio por SARS-CoV-2 en África en comparación con los otros continentes, incluso la proporción de contagios en el personal de salud ha sido de $12 \%$ en Malawi, lo que se compara a la de Lombardía (10\%). Se ha observado que en la población de Mozambique se encuentra entre 3\% a 10\% de sensibilización al SARS-CoV-2, siendo el país con la tasa de mortalidad más baja de África[12].

Se destaca que en África hay mucho menos pacientes hospitalizados en unidades de cuidados intensivos o fallecidos que en muchas otras partes del mundo, contradiciendo las opiniones de expertos que preveían una gran catástrofe. Y frente a esto, se han esgrimido una serie de hipótesis que se presentarán a continuación, y frente a cada una de ellas aún no se cuenta con un respaldo científico adecuado:

- Los jóvenes tienen menos síntomas del COVID-19 y el promedio de edad en la población africana es bajo. Lo cual no ha sido apreciado en Estados Unidos o Europa, donde han ingresado a los cuidados intensivos pacientes jóvenes de ascendencia africana.

- Los africanos se benefician de una inmunidad especial debido a numerosos contactos con otros Coronavirus. En el hemisferio norte, la causa más frecuente de los estados gripales son los Coronavirus.
- Existe un subregistro en África, ya que la mayoría de las personas mueren en sus pueblos, sin diagnóstico. Muchos países africanos tienen sistemas estadísticos adecuados en materia de salud. Es así como en Burundí, solo se ha tenido hasta la fecha que un solo fallecido por COVID-19, y tiene una tasa de contagiosidad milagrosamente baja, lo cual ha sido ratificado por los médicos locales consultados. Esta realidad contrasta completamente con países vecinos como Tanzania. Claramente, la información es escasa de los países en guerra o en estado de inestabilidad social como Libia, Mali, Sudán del Sur, República de Centroáfrica, RD del Congo y Zimbabue.

- La Genética es particular. Un artículo publicado en Nature[19] el 30 de septiembre de 2020 mostró que un gen de riesgo para desarrollar una forma grave de COVID-19 está ausente en el patrimonio genético de la población del África subsahariana. Este gen, situado en el cromosoma 3, está presente en una minoría de la población europea, el cual sería una herencia del mestizaje entre el Homosapiens y una rama croata del hombre de Neanderthal de hace unos 50.000 años. Así el Homo Sapiens se expandió a lo largo de África, y parte de Asia oriental. Se ha encontrado una muy alta prevalencia del gen en Bengla Desh, e incluso en los inmigrantes de este país en el Reino Unido han presentado una muy alta mortalidad al COVID-19 (Figura 6).

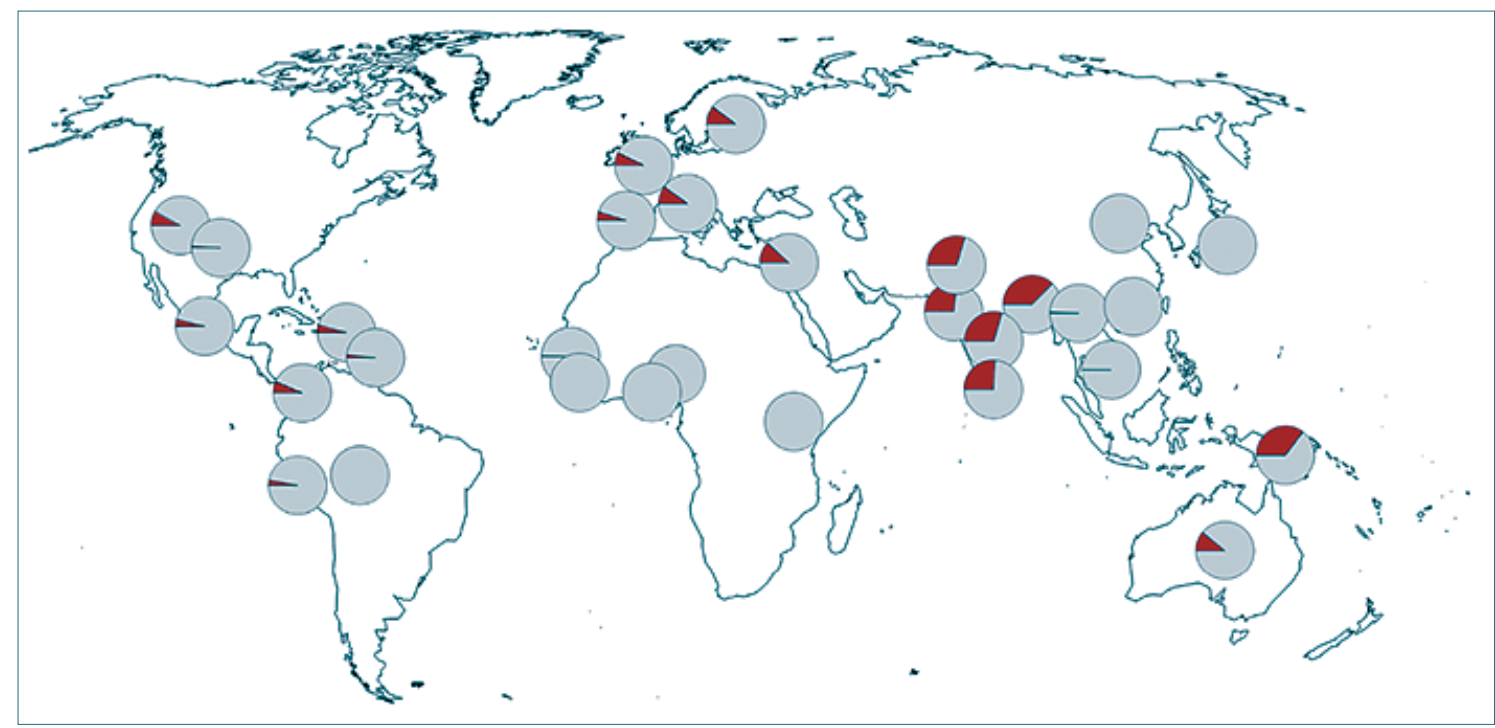

Figura 6. Distribución geográfica del haplotipo nuclear ligado al riesgo de desarrollo de una forma severa del COVID-19. LoS puntos en rojo indican las frecuencias del alelo en poblaciones nativas. Mapa reproducido de Nature. 
Por último, los gobiernos de la África sub-saharina reducen sus medidas muy progresivamente basados en la experiencia de Marruecos, donde comienzan lentamente a abrir sus fronteras. Siendo la primera prioridad[21] el restablecer una escolaridad normal, antes de autorizar las actividades de los adultos no esenciales. Esto se basa en el principio que ocupar los niños en el colegio, permitirá a sus padres trabajar para alimentar a sus familias, y a la vez, escolarizar, permite reducir ciertas inequidades sociales, ya que frecuentemente, en la escuela se entregan alimentos a los niños. El gran fundamento es proteger a los niños, así como, restablecer el derecho a la educación como expresión futura de la libertad humana.

\section{Referencias}

1. Michel, Beuret. La Chinafrique: Pékin à la conquête du continent noir. Grasset 2008. ISBN-10: $2246736218 \& 19$

2. Cummings MJ, Baldwin MR, Abrams D, Jacobson SD, Meyer BJ, Balough EM, et al. Epidemiology, clinical course, and outcomes of critically ill adults with COVID-19 in New York City: a prospective cohort study. Lancet. 2020 Jun;395(10239):176370. https://doi.org/10.1016/ s0140-6736(20)31189-2 PMID:32442528

3. Delanghe JR, Speeckaert MM, De Buyzere ML. COVID-19 infections are also affected by human ACE1 D/I polymorphism [CCLM]. Clin Chem Lab Med. 2020 Jun;58(7):1125-6. https://doi. org/10.1515/cclm-2020-0425 PMID:32286246

4. Vaduganathan $M$, Vardeny $O$, Michel T, McMurray JJ, Pfeffer MA, Solomon SD. ReninAngiotensin-Aldosterone System Inhibitors in Patients with Covid-19. N Engl J Med. 2020 Apr;382(17):1653-9. https://doi. org/10.1056/NEJMsr2005760 PMID:32227760

5. Zhang $\mathrm{H}$, Penninger JM, Li Y, Zhong N, Slutsky AS. Angiotensin-converting enzyme 2 (ACE2) as a SARS-CoV-2 receptor: molecular mechanisms and potential therapeutic target. Intensive Care Med. 2020 Apr;46(4):586-90. https://doi.org/10.1007/s00134-
020-05985-9 PMID:32125455

6. El-Sadr WM, Justman J. Africa in the Path of Covid-19. N Engl J Med. 2020 Jul;383(3):e11. https://doi.org/10.1056/NEJMp2008193 PMID:32302075

7. Fry $\mathrm{H}$, Abdelmoneim J. Contagion: BBC Documentary 2018, experiment designed and analyzed by the University of Cambridge and the London School of Hygiene and Tropical Medicine www.youtube.com/ watch?v=RmGiDUczhqQ

8. Ferguson $\mathrm{N}$ et al., Impact of nonpharmaceutical interventions to reduce covid19 mortality and healthcare demand. Imperial College Response Team Report 9: 16 March 2020 d

9. Mitze T, et al. Face Masks Considerably Reduce Covid-19 Cases in Germany: a Synthetic Control Method Approach. IZA (Institute of Labor Economics) DP 13319 June 2020; ISSN 2365-9793.

10. Ahounou E. "We have to put all our bets on prevention" https:// www.kbs-frb.be/en/Newsroom/ Stories/20200604ND

11. Maxmen A. Liberia, Sierra Leone and Guinea: ebola prepared these countries for coronavirus - but now even they are floundering. NATNEWS. 2020 Jul.

12. Nordling $L$. The pandemic appears to have spared Africa so far. Scientists are struggling to explain why. Science. 2020 Aug. https:// doi.org/10.1126/science.abe2825.

13. Uyoga $S$, et al. Seroprevalence of anti-SARS-CoV-2 IgG antibodies in Kenyan blood donors. medRxiv. Preprint https://doi.org/10 .1101/2020.07.27.20162693. Posted July 29, 2020

14. Marah G. Chibwana et al. High SARS-CoV-2 seroprevalence in health care workers but relatively low numbers of deaths in urban Malawi medRxiv preprint

15. Grifoni A, Weiskopf D, Ramirez SI, Mateus J, Dan JM, Moderbacher CR, et al. Targets of $T$ Cell Responses to SARS-CoV-2 Coronavirus in Humans with COVID-19 Disease and Unexposed Individuals. Cell. 2020 Jun;181(7):14891501.e15. https://doi. org/10.1016/j.cell.2020.05.015 PMID:32473127

16. World Health Organization. Bacille Calmette-Guérin (BCG) vaccination and COVID-19. Available from: https://www.who.int/ news-room/commentaries/detail/ bacille- calmette-guérin-(bcg)vaccination-and-covid-19.

17. Kumar J, Meena J. Demystifying BCG Vaccine and COVID-19 Relationship. Indian Pediatrics. Springer Science and Business Media LLC; 2020 Apr 30;57(6):588-9. http://dx.doi. org/10.1007/s13312-020-18720

18. Sette A, Crotty S. Pre-existing immunity to SARS-CoV-2: the knowns and unknowns. Nat Rev Immunol. 2020 Aug;20(8):457-8. https://doi. org/10.1038/s41577-020-0389-z PMID:32636479 
19. Zeberg H, Pääbo S. The major genetic risk factor for severe COVID-19 is inherited from Neandertals. Cold Spring Harbor Laboratory; 2020 Jul 3; http://dx.doi. $\mathrm{rg} / 10.1101 / 2020.07 .03 .186296$
20. Public Health England. Disparities in the risk and outcomes of COVID-19. (2020). https://www. gov.uk/government/publications/ covid-19-review-of-disparities-inrisks-and-outcomes

21. Levinson $M$, Cevik M, Lipsitch
M. Reopening Primary Schools during the Pandemic. Malina $D$, editor. New England Journal of Medicine. Massachusetts Medical Society; 2020 Sep 3;383(10):981-5. http://dx.doi. org/10.1056/nejmms2024920 